\title{
Multivariate analysis to simplify the differential diagnosis of broad complex tachycardia
}

\author{
Michael J Griffith, Mark A de Belder, Nicholas J Linker, David E Ward, A John Camm
}

\begin{abstract}
Univariate analysis has identified several criteria that aid the differential diagnosis of broad complex tachycardia. In this study of 102 consecutive patients multivariate analysis was performed to identify which of 15 clinical and 11 electrocardiographic variables were independent predictors of ventricular tachycardia. These were shown to be a history of myocardial infarction, the QRS waveforms in leads aVF and V1, and a change in axis from sinus rhythm to tachycardia of more than $40^{\circ}$. If none of the criteria was met, the diagnosis was almost certainly supraventricular tachycardia. If one criterion was met the diagnosis was probably supraventricular tachycardia. If two criteria were met then the diagnosis was probably ventricular tachycardia. If three or four criteria were met, the diagnosis was almost certainly ventricular tachycardia. The predictive accuracy was $93 \%$. This was increased to $95 \%$ by including two other criteria-definite independent $P$ wave activity and ventricular extrasystoles with the same QRS configuration as that in tachycardia. These criteria were not included in the multivariate analysis because though they were $100 \%$ specific they were seldom seen.
\end{abstract}

These four criteria can be used as simple rules in determining the origin of a broad complex tachycardia.

All previous studies on the electrocardiographic or clinical diagnosis of broad complex tachycardias have used univariate analysis to assess the value of individual diagnostic criteria. $^{1-8}$ The aim of this study was to investigate the interaction between variables and, by use of multivariate analysis, to identify the independent predictors of the diagnosis of ventricular tachycardia.

\section{Patients and methods}

PATIENTS

Data were collected prospectively from 102 consecutive patients referred to St George's Hospital for investigation of their tachycardia between November 1986 and November 1988. Each patient had a 12 lead electrocardiogram showing broad complex uniform tachycardia (QRS width greater than $110 \mathrm{~ms}$ ) and the definitive diagnosis was established at electrophysiological study with two to four transvenous intracardiac electrodes. The diagnosis was supraventricular tachycardia if a His potential preceded each ventricular electrogram, with a normal HV interval, or if anterograde conduction down an atrioventricular or nodoventricular accessory pathway was shown. If no His potential preceded each ventricular electrogram or the HV interval was shorter than that seen during sinus rhythm then the diagnosis was ventricular tachycardia. If a patient had tachycardia with more than one configuration, the tachycardia recorded at first presentation was analysed. Patients who had sustained a myocardial infarct in the previous seven days were excluded. The clinical data that were available on presentation were collected. These included features obtained from the history and a chest $x$ ray. Secondary information that was available from the patients' records was also analysed. Electrocardiograms in both tachycardia and sinus rhythm were collected and analysed.

CLINICAL DATA

Features of the history that were assessed included:

(a) Age at presentation to St George's Hospital.

(b) A history of congestive heart failuredefined as an episode of exertional breathlessness, orthopnoea, or paroxysmal nocturnal dyspnoea (in the absence of chronic lung disease), not associated with palpitation.

(c) A history of angina pectoris-defined on the basis of classic symptoms when the patient was not in tachycardia.

(d) A history of coronary artery bypass grafting.

(e) A previous myocardial infarct-defined as any specific episode when the patient had been admitted to hospital with chest pain and believed that he had sustained a heart attack.

$(f)$ Palpitation-defined as any history of irregular or fast heart beats.

(g) Syncope-defined as any episode of loss of consciousness whether or not this was related to tachycardia.

(h) Smoking-including current smokers and those who had given up in the year before presentation.

(i) A family history of ischaemic heart disease-defined as any first degree relative with angina, a previous heart attack, or who had undergone coronary artery bypass surgery.

(j) Chest pain during tachycardia. 
(k) Collapse during tachycardia-defined as either loss of consciousness or a systolic blood pressure of $<60 \mathrm{~mm} \mathrm{Hg}$.

In addition we noted the following results of investigation:

(a) The cardiothoracic ratio-calculated conventionally from the presentation posteroanterior chest radiograph taken during sinus rhythm (an abnormal ratio was defined as $>0.55)$.

(b) A left ventricular aneurysm-if documented on echocardiography or cardiac catheterisation.

\section{ELECTROCARDIOGRAPHIC DATA}

The electrocardiograms were recorded at a paper speed of $25 \mathrm{~mm} / \mathrm{s}$ because this is the conventional speed of recording used in clinical practice. The following variables were measured:

(a) Width of the QRS-defined as the widest measurable QRS complex.

(b) RR interval during tachycardia, averaged over four beats.

(c) Regularity of tachycardia-defined as the maximum difference in $R R$ interval over five consecutive beats (excluding fusion or capture beats), measured in a lead with a sharp $R$ wave peak.

(d) Fusion or capture beats-defined conventionally.

(e) Independent $\mathrm{P}$ waves-these had to be approximately regular with a different rate from that of the QRS complexes.

(f) "Bundle branch block" pattern during tachycardia-defined on the basis of the dominant deflection in lead V1; if the QRS complex was predominantly positive, "right bundle branch block" pattern was assigned, and if it was predominantly negative it was "left bundle branch block" pattern.

(g) Ventricular extrasystoles-defined as wide complex beats in sinus rhythm without a preceding $\mathbf{P}$ wave (these extrasystoles could have been aberrantly conducted atrioventricular junctional complexes). The configuration of these beats was compared with that of the QRS complex during tachycardia in those leads in which they were recorded.

(h) QRS axis-measured in the frontal plane using the dominant vector in each of the six limb leads. A "normal" axis was defined as from $-30^{\circ}$ to $+90^{\circ}$, right axis as $+90^{\circ}$ to $180^{\circ}$, and left axis as $-30^{\circ}$ to $-180^{\circ}$.

(i) Change in QRS axis-defined as a difference in axis of greater than $40^{\circ}$ between sinus rhythm and tachycardia.

(j) Fusion beats-defined as complexes in tachycardia that have a QRS waveform intermediate between the configuration seen during tachycardia and that expected from conduction down the atrioventricular node.

In the "left bundle branch block" tachycardias, leads V1, V2, and V6 were analysed on the basis of the criteria described by Wellens and colleagues and tested by Kindwall and coworkers. ${ }^{12}$

The configurations recorded from the leads I, aVF, V1, and V6 were based on the number, order, and relative magnitude of the $Q, R$, and
$S$ waves and assigned to one of 12 basic waveforms (fig 1).

\section{ANALYSIS}

Each variable was initially examined by univariate analysis for its predictive ability in the diagnosis of ventricular tachycardia. The $\chi^{2}$ test was used to test differences between proportions and Student's unpaired $t$ test was used to test for differences between continuous variables. Significance was defined at the $\mathrm{p}<0.05$ level.

The configuration of the QRS complexes (112 ) in the four selected leads was analysed with respect to the final diagnosis. For each lead the number of patients with each pattern who had ventricular or supraventricular tachycardia was counted and an estimated ventricular to supraventricular tachycardia ratio (the VT/ SVT ratio) was calculated. Overall in this study, 69 patients had a definitive diagnosis of ventricular tachycardia and 33 patients had supraventricular tachycardia, providing a true $\mathrm{VT} / \mathrm{SVT}$ ratio of $2 / 1$. If the estimated VT/ SVT ratio of a pattern in a lead was $2 / 1$ or greater this waveform was defined as diagnostic of ventricular tachycardia in that lead; if the ratio was less than $2 / 1$ the waveform was defined as diagnostic of supraventricular tachycardia. This classification was necessary so that the individual lead configurations could be entered into the multivariate analysis.

It may be argued that these electrocardiographic criteria were derived from the data. Therefore a second analysis was also performed using an a priori classification of electrocardiographic configuration derived from

\begin{tabular}{|c|c|c|c|}
\hline \multicolumn{2}{|c|}{ Number } & \multirow{2}{*}{ Waveform } & \multirow{2}{*}{$\begin{array}{l}\text { Description } \\
\text { Single R wave }\end{array}$} \\
\hline 1 & $R$ & & \\
\hline 2 & Rs & & $R>S$ \\
\hline 3 & rS & & $S>r$ \\
\hline 4 & RSr' & & $R>r^{\prime}$ \\
\hline 5 & rSR' & & $R^{\prime}>r$ \\
\hline 6 & $\mathrm{RSR}^{\prime}$ & & $R^{\prime}=R$ \\
\hline 7 & OS & & as \\
\hline 8 & qR & & $R>q$ \\
\hline 9 & Or & & $Q>r$ \\
\hline 10 & QRs & & $Q>s$ \\
\hline 11 & qRS & & $S>q$ \\
\hline
\end{tabular}


published reports. These are only available for leads V1 and V6. ${ }^{124}$ For V1 the diagnostic waveforms were identical to those derived from our data in patients with "right bundle branch block" tachycardia ${ }^{14}$ (see figure 5) and these were combined with the criteria for ventricular tachycardia of Kindwall and colleagues ${ }^{2}$ in patients with "left bundle branch block" pattern tachycardia. In lead V6 a $Q$ wave or dominant $S$ wave were classified as ventricular tachycardia (configurations 3 and 7-12) and those with a dominant $R$ wave as supraventricular tachycardia (configurations $1,2,4$, 5 , and 6). ${ }^{124}$ This classification had minor differences from the derived criteria for V6.

All variables that were significant by univariate analysis were then entered into multivariate analysis. However, all patients in this study who had a history of congestive heart failure, angina pectoris, or coronary artery surgery also had either a history of myocardial infarction or an abnormal cardiothoracic ratio. The latter two variables were the most powerful predictors of the diagnosis of ventricular tachycardia; the addition of the three other variables did not increase either sensitivity or specificity. Previous myocardial infarction and an abnormal cardiothoracic ratio were therefore included in the multivariate analysis in preference to the other three variables.

Independent $P$ wave activity and ventricular extrasystoles with the same configuration as tachycardia were not included in the multivariate analysis because both were $100 \%$ specific for ventricular tachycardia and were thus diagnostic. With an iterative approach it is difficult to compare these latter two variables with other variables with less than $100 \%$ specificity. They were added to the final analysis, however, to evaluate whether they would improve the diagnostic capability. The multivariate analysis was performed with the logit model (using the LIMDEP package, version IV.2, on a personal computer $\left.{ }^{9}\right)$. This uses stepwise logistic regression to generate probabilistic functions for a binary result. This system, because it uses logistic rather than linear regression, allows the analysis of both continuous and non-continuous variables. ${ }^{111}$ In the LOGIT model the probability $(P)$ of an event occurring is expressed as the non-linear function, $1 /[1+\exp (-B . X)]$, of observable characteristics $(X)$ and coefficients $(B)$. The model requires a constant term, termed "constant" in the tables, which is analogous to the intercept term in least squares regression.

\section{Results}

Table 1 shows the results of univariate analysis. Many of the variables were significantly different between ventricular tachycardia and supraventricular tachycardia. Patients with ventricular tachycardia were older and were more likely to have a history of congestive heart failure, angina pectoris, coronary artery surgery, myocardial infarction, smoking, and haemodynamic collapse during the attack. They were also more likely to have an abnormal cardiothoracic ratio and a left ventricular aneurysm. The following features were electrocardiographic markers of ventricular tachycardia: the width of the QRS complex during tachycardia, the presence of independent $\mathbf{P}$ waves during tachycardia, ventricular extrasystoles with the same configuration as the QRS in tachycardia, left axis deviation during tachycardia, and an axis shift of greater than $40^{\circ}$ from sinus rhythm to tachycardia. Fusion beats were seen in supraventricular tachycardia in three patients (fig 2).

Table 2 shows the incidence of the various defined waveforms in leads I, aVF, V1, and V6; and table 3 shows the estimated VT/SVT ratio for each configuration in each lead and the designated diagnosis. Certain waveforms were more predictive for each diagnosis than others.

Lead I-In "left bundle branch block" pattern tachycardia a QS or qR wave (pattern 7 or 8) was seen only in ventricular tachycardia. This lead was not helpful, however, in making the diagnosis in "right bundle branch block" pattern tachycardia.

Lead aVF-In tachycardia with a "left bundle branch block" pattern a QS or qR wave (pattern 7 or 8 ) was highly suggestive of ventricular tachycardia, while an $\mathrm{Rs}$ wave (pattern 2) was specific for supraventricular tachycardia. In "right bundle branch block" pattern tachycardia a predominantly negative

Table 1 Results of univariate analysis

\begin{tabular}{|c|c|c|c|}
\hline Variable & $V T$ & $S V T$ & p Value \\
\hline $\begin{array}{l}\text { Age }(y r)(\operatorname{mean}(S D)) \\
\text { Sex } F / M\end{array}$ & $\begin{array}{l}54.2(16) \\
14 / 55\end{array}$ & $\begin{array}{l}31.9(15) \\
7 / 26\end{array}$ & $\begin{array}{l}0.001 \\
0.91\end{array}$ \\
\hline \multicolumn{4}{|c|}{ History of: } \\
\hline Cardiac failure & $16 / 69^{\star}$ & $0 / 33$ & 0.001 \\
\hline Angina & $22 / 69^{\star}$ & $1 / 33$ & 0.001 \\
\hline Coronary surgery & $9 / 69^{\star}$ & $0 / 33$ & 0.01 \\
\hline Myocardial infarct & $44 / 69$ & $1 / 33$ & 0.001 \\
\hline Palpitation & $49 / 69$ & $28 / 33$ & 0.13 \\
\hline Syncope & $29 / 69$ & $12 / 33$ & 0.59 \\
\hline Smoking & $32 / 69$ & $8 / 33$ & 0.05 \\
\hline Family history & $15 / 69$ & $6 / 32$ & 0.95 \\
\hline Aneurysm & $14 / 69 \dagger$ & $0 / 33$ & 0.001 \\
\hline \multicolumn{4}{|l|}{ During tachycardia: } \\
\hline & $18 / 69$ & $10 / 33$ & 0.45 \\
\hline $\begin{array}{l}\text { Hypotension } \\
\text { CTR }>0.55\end{array}$ & $\begin{array}{l}25 / 69 \\
33 / 69\end{array}$ & $\begin{array}{l}4 / 33 \\
1 / 33\end{array}$ & $\begin{array}{l}0.05 \\
0.001\end{array}$ \\
\hline & \multicolumn{3}{|c|}{ ECG variables: } \\
\hline \multirow{2}{*}{\multicolumn{4}{|c|}{$\begin{array}{l}\text { Mean (SD) QRS } \\
\text { complex width (ms) in: }\end{array}$}} \\
\hline & & & \\
\hline Tachycardia & $156(38)$ & $131(20)$ & 0.001 \\
\hline $\begin{array}{l}\text { Sinus rhythm } \\
\text { S }\end{array}$ & $101(22)$ & $101(22)$ & 0.93 \\
\hline \multicolumn{4}{|l|}{$\begin{array}{l}\text { Tachycardia: } \\
\text { Mean (SD) }\end{array}$} \\
\hline RR interval (ms) & & & \\
\hline Regularity (ms) & $11 \cdot 2(10)$ & $22(59)$ & 0.76 \\
\hline Fusion/capture & $13 / 69$ & & 0.41 \\
\hline $\begin{array}{l}\text { Independent } P \\
\text { waves }\end{array}$ & $23 / 69$ & $0 / 33$ & 0.001 \\
\hline LBBB pattern & $36 / 69$ & $176 / 33$ & 0.94 \\
\hline RBBB pattern & $33 / 69$ & $16 / 33$ & 0.94 \\
\hline VES with same & $12 / 69$ & & \\
\hline \multirow{2}{*}{\multicolumn{4}{|c|}{$\begin{array}{l}\text { Axis during } \\
\text { tachycardia: }\end{array}$}} \\
\hline & & & \\
\hline & & & \\
\hline $\begin{array}{l}\text { Normal axis } \\
\text { Right axis }>+90^{\circ}\end{array}$ & $21 / 69$ & $9 / 33$ & \\
\hline Left axis $<-30^{\circ}$ & $43 / 69$ & $10 / 33$ & 0.01 \\
\hline \multicolumn{4}{|c|}{$\begin{array}{l}\text { Axis shift from sinus } \\
\text { rhythm to tachycardia: }\end{array}$} \\
\hline $\begin{array}{c}\text { rhythim to tachycardia: } \\
-40^{\circ} \text { to }+40^{\circ}\end{array}$ & $12 / 69$ & $21 / 69$ & \\
\hline$>40^{\circ}$ & $21 / 69$ & $5 / 33$ & 0.001 \\
\hline$<-40^{\circ}$ & $36 / 69$ & $7 / 33$ & \\
\hline
\end{tabular}

*All these patients had a history of myocardial infarction or an abnormal cardiothoracic ratio (these variables were not included in the multivariate analysis).

†Not included in the multivariate analysis as not necessarily available at presentation.

available at presentation. systole; LBBB, left bundle branch block; RBBB, right bundle branch block. 
Figure 2

Supraventricular tachycardia

(atrioventricular reentry tachycardia) with "fusion" beats caused by intermittent partial right bundle branch block interrupting complete right bundle branch block.

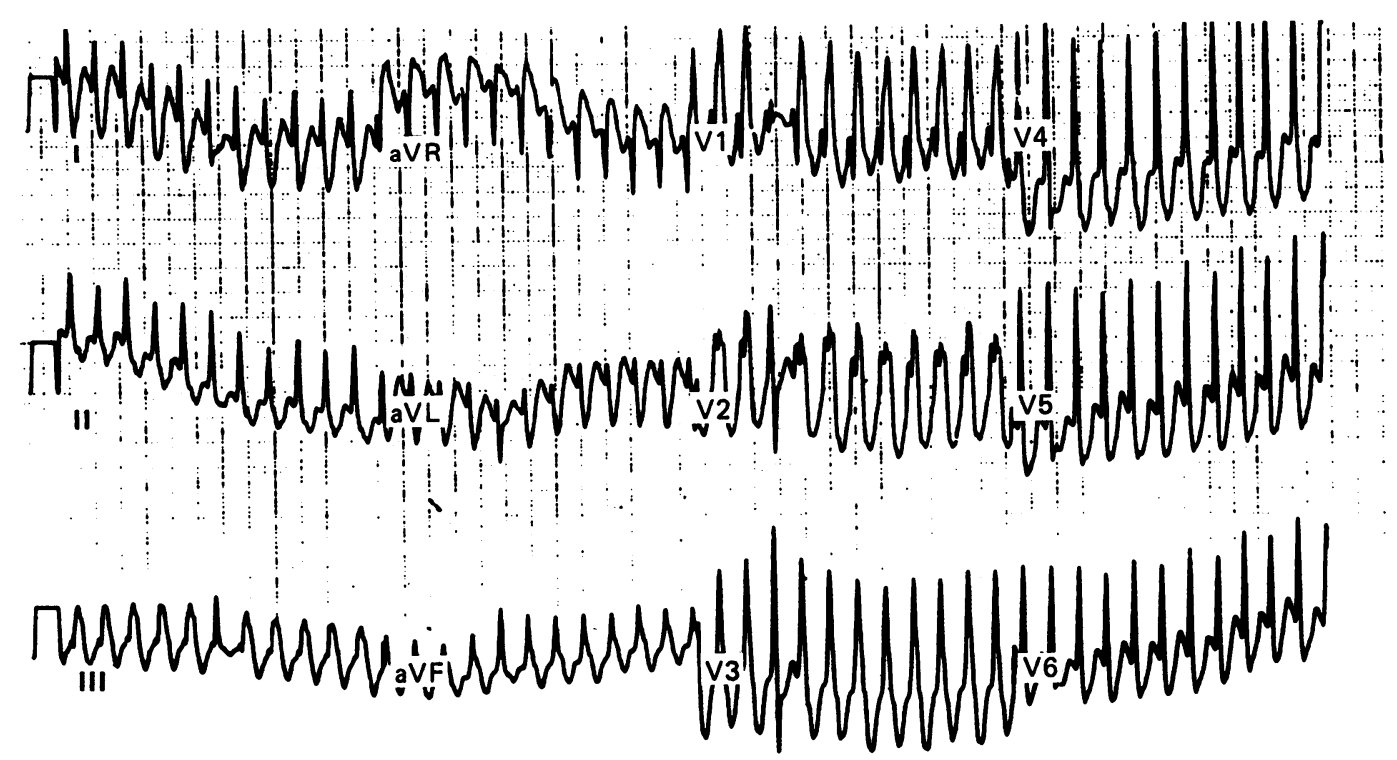

deflection was suggestive of ventricular tachycardia, especially when a $Q$ wave was present (patterns 7, 9, and 10). Figures 3 and 4 show the predictive waveforms.

Lead VI-In "left bundle branch block" pattern tachycardia the waveform alone was not helpful in making a diagnosis. In "right bundle branch block" pattern tachycardia, a monophasic or biphasic waveform suggested ventricular tachycardia (patterns 1,2 , or 8); a triphasic $\mathbf{R s R}^{\prime}$ or $\mathrm{rSR}^{\prime}$ configuration suggested supraventricular tachycardia (pattern 5 or 6), unless the amplitude of the $R$ wave was greater than that of the $R^{\prime}$ wave (pattern 4). Figure 5 shows the predictive waveforms.

Lead V6-Overall this lead was not helpful in making the diagnosis in "left bundle branch block" pattern tachycardia, although a $Q$ wave was specific for ventricular tachycardia (patterns 7-11). In "right bundle branch block" pattern tachycardia a $Q$ wave (pattern 7 or 8) or an RS wave with $S>R$ (pattern 3) was suggestive of ventricular tachycardia. Table 4 shows the predictive accuracy of each lead when the above criteria were used. Lead aVF had the highest predictive accuracy $(73 \%)$; the other three leads each had a predictive accuracy of around $60 \%$.

\section{A PRIORI ELECTROCARDIOGRAPHIC CRITERIA}

Table 4 shows the predictive accuracy of the QRS configuration classification based on published reports on leads V1 and V6. The predictive accuracy of V6 was very similar to that with the derived criteria at $66 \%$. The high level of predictive accuracy for V1 $(78 \%)$ was because this combined the criteria based on configuration and the criteria based on the initial $R$ and $S$ wave duration.

\section{MULTIVARIATE ANALYSIS}

Table 5 shows the results of multivariate analysis of the clinical data. Beta is the coefficient that is entered into the logistic regression equation. A history of myocardial infarction and an abnormal cardiothoracic ratio were the only independent predictors of the diagnosis of ventricular tachycardia.

Table 5 also shows the results of the multivariate analysis of the electrocardiographic data. The Kindwall criteria for "left bundle branch block" tachycardia; the specific waveforms in leads aVF, V1, and V6; and change in axis between sinus rhythm and tachycardia were independent predictors of ventricular tachycardia.

Table 5 also gives the results of multivariate

Table $2 Q R S$ waveforms in the patients with either supraventricular tachycardia (SVT) or ventricular tachycardia (VT) analysed separately for "left bundle branch block" (LBBB) and "right bundle branch block" (RBBB) patterns

\begin{tabular}{|c|c|c|c|c|c|c|c|c|c|c|c|c|c|c|c|c|c|}
\hline \multirow{3}{*}{\multicolumn{2}{|c|}{ Waveform }} & \multicolumn{4}{|l|}{$I$} & \multicolumn{4}{|l|}{$a V F$} & \multicolumn{4}{|l|}{$V 1$} & \multicolumn{4}{|l|}{ V6 } \\
\hline & & \multicolumn{2}{|c|}{$L B B B$} & \multicolumn{2}{|c|}{$R B B B$} & \multicolumn{2}{|c|}{$L B B B$} & \multicolumn{2}{|c|}{$R B B B$} & \multicolumn{2}{|l|}{$L B B B$} & \multicolumn{2}{|c|}{$R B B B$} & \multicolumn{2}{|c|}{$L B B B$} & \multicolumn{2}{|c|}{$R B B B$} \\
\hline & & $S V T$ & $V T$ & $S V T$ & $V T$ & $S V T$ & $V T$ & $S V T$ & $V T$ & $S V T$ & $V T$ & $S V T$ & $V T$ & $S V T$ & $V T$ & $S V T$ & $V T$ \\
\hline $\begin{array}{r}1 \\
2 \\
3 \\
4 \\
5 \\
6 \\
7 \\
8 \\
9 \\
10 \\
11 \\
12\end{array}$ & $\begin{array}{l}\text { R } \\
\text { Rs } \\
\text { rS } \\
\text { RSr } \\
\text { rSR } \\
\text { RsR } \\
\text { QS } \\
\text { qR } \\
\text { Qr } \\
\text { QRs } \\
\text { qRS } \\
\text { 4X }\end{array}$ & $\begin{array}{r}12 \\
1 \\
1 \\
0 \\
0 \\
2 \\
0 \\
0 \\
1 \\
0 \\
0 \\
0\end{array}$ & $\begin{array}{r}16 \\
1 \\
4 \\
0 \\
0 \\
3 \\
5 \\
5 \\
0 \\
1 \\
0 \\
0\end{array}$ & $\begin{array}{l}1 \\
5 \\
7 \\
0 \\
0 \\
0 \\
2 \\
0 \\
0 \\
0 \\
0 \\
1\end{array}$ & $\begin{array}{r}2 \\
8 \\
18 \\
0 \\
0 \\
0 \\
3 \\
0 \\
0 \\
0 \\
2 \\
1\end{array}$ & $\begin{array}{l}6 \\
4 \\
3 \\
0 \\
0 \\
0 \\
4 \\
0 \\
0 \\
0 \\
0 \\
0\end{array}$ & $\begin{array}{r}12 \\
0 \\
3 \\
0 \\
1 \\
1 \\
15 \\
3 \\
0 \\
0 \\
0 \\
0\end{array}$ & $\begin{array}{l}4 \\
2 \\
3 \\
1 \\
1 \\
1 \\
1 \\
2 \\
1 \\
0 \\
0 \\
1\end{array}$ & $\begin{array}{r}5 \\
1 \\
5 \\
1 \\
0 \\
0 \\
16 \\
1 \\
2 \\
2 \\
0 \\
1\end{array}$ & $\begin{array}{l}0 \\
0 \\
9 \\
0 \\
0 \\
0 \\
8 \\
0 \\
0 \\
0 \\
0 \\
0\end{array}$ & $\begin{array}{r}0 \\
0 \\
17 \\
0 \\
0 \\
0 \\
14 \\
0 \\
1 \\
2 \\
1 \\
0\end{array}$ & $\begin{array}{l}2 \\
2 \\
0 \\
0 \\
9 \\
2 \\
0 \\
1 \\
0 \\
0 \\
0 \\
0\end{array}$ & $\begin{array}{r}12 \\
4 \\
0 \\
2 \\
3 \\
0 \\
0 \\
10 \\
0 \\
1 \\
1 \\
1\end{array}$ & $\begin{array}{r}10 \\
2 \\
3 \\
0 \\
0 \\
2 \\
0 \\
0 \\
0 \\
0 \\
0 \\
0\end{array}$ & $\begin{array}{r}15 \\
4 \\
3 \\
0 \\
0 \\
3 \\
2 \\
3 \\
0 \\
2 \\
3 \\
0\end{array}$ & $\begin{array}{l}4 \\
8 \\
3 \\
0 \\
0 \\
0 \\
1 \\
0 \\
0 \\
0 \\
0 \\
0\end{array}$ & $\begin{array}{r}1 \\
5 \\
14 \\
0 \\
0 \\
0 \\
12 \\
1 \\
0 \\
0 \\
0 \\
1\end{array}$ \\
\hline
\end{tabular}


Table $3 V T / S V T$ ratio in each lead and the assigned diagnosis of ventricular (VT) or supraventricular tachycardia (SVT) for "left bundle branch block" (LBBB) and "right bundle branch block" (RBBB) pattern tachycardias

\begin{tabular}{|c|c|c|c|c|c|c|c|c|c|c|c|c|c|c|c|c|c|}
\hline \multirow{2}{*}{\multicolumn{2}{|c|}{ Waveform }} & \multicolumn{4}{|l|}{$I$} & \multicolumn{4}{|c|}{$a V F$} & \multicolumn{4}{|l|}{$V 1$} & \multicolumn{4}{|l|}{ V6 } \\
\hline & & \multicolumn{2}{|c|}{$\begin{array}{l}\angle B B B \\
\text { ratio/ } \\
\text { diagnosis }\end{array}$} & \multicolumn{2}{|c|}{$\begin{array}{l}R B B B \\
\text { ratio/ } \\
\text { diagnosis }\end{array}$} & \multicolumn{2}{|c|}{$\begin{array}{l}L B B B \\
\text { ratiol } \\
\text { diagnosis }\end{array}$} & \multicolumn{2}{|c|}{$\begin{array}{l}R B B B \\
\text { ratio/ } \\
\text { diagnosis }\end{array}$} & \multicolumn{2}{|c|}{$\begin{array}{l}L B B B \\
\text { ratiol } \\
\text { diagnosis }\end{array}$} & \multicolumn{2}{|c|}{$\begin{array}{l}R B B B \\
\text { ratio/ } \\
\text { diagnosis }\end{array}$} & \multicolumn{2}{|c|}{$\begin{array}{l}\angle B B B \\
\text { ratio/ } \\
\text { diagnosis }\end{array}$} & \multicolumn{2}{|c|}{$\begin{array}{l}R B B B \\
\text { ratio/ } \\
\text { diagnosis }\end{array}$} \\
\hline 1 & $\mathbf{R}$ & $1 \cdot 3$ & SVT & 2 & VT & 2 & VT & 1.25 & SVT & - & - & 6 & VT & 1.5 & SVT & 0.25 & SVT \\
\hline 2 & Rs & 1 & SVT & 1.6 & SVT & $\star$ & SVT & 0.5 & SVT & - & - & 2 & VT & 2 & $\mathrm{VT}$ & 0.6 & SVT \\
\hline 3 & $\mathrm{rS}$ & 4 & VT & $2 \cdot 6$ & VT & 1 & SVT & $1 \cdot 7$ & SVT & 1.9 & SVT & - & - & 1 & SVT & $4 \cdot 7$ & VT \\
\hline 4 & RSr & - & - & - & - & - & - & 1 & SVT & - & - & - & - & $\star$ & SVT & - & - \\
\hline 5 & rSR & - & - & - & - & $t$ & VT & $\star$ & SVT & - & - & 0.3 & SVT & - & - & - & - \\
\hline 6 & RsR & 1.5 & SVT & - & - & $\dagger$ & VT & $\star$ & SVT & - & - & $\star$ & SVT & 1.5 & SVT & - & - \\
\hline 7 & QS & $\dagger$ & VT & 1.5 & SVT & 3.8 & VT & 16 & VT & $1 \cdot 8$ & SVT & - & - & $\dagger$ & VT & 12 & VT \\
\hline 8 & $\mathrm{qR}$ & $t$ & VT & - & - & $\dagger$ & $\mathrm{VT}$ & 0.5 & SVT & - & - & 10 & VT & $\dagger$ & VT & $\dagger$ & VT \\
\hline 9 & Qr & $\star$ & SVT & - & - & - & - & 2 & VT & $t$ & VT & - & - & - & - & - & - \\
\hline 10 & QRs & $\dagger$ & VT & - & - & - & - & $\dagger$ & VT & $t$ & VT & $\dagger$ & VT & $\dagger$ & VT & - & - \\
\hline 11 & $\mathrm{qRS}$ & - & - & $\dagger$ & VT & - & - & - & - & $\dagger$ & VT & $\dagger$ & VT & $\dagger$ & VT & - & - \\
\hline 12 & $4 X$ & - & - & 1 & SVT & - & - & 1 & SVT & - & - & $\dagger$ & VT & - & - & $\dagger$ & VT \\
\hline
\end{tabular}

$\star$ Only patients with SVT had this waveform in this lead; fonly patients with VT had this waveform in this lead. For waveforms see figure 2.

analysis of all the significant predictors, both clinical and electrocardiographic. A history of myocardial infarction, the specific QRS configurations in leads VI and $\mathrm{aVF}$, and the change in axis from sinus rhythm to tachycardia remained independent predictors of ventricular tachycardia.

A repeat analysis was performed with only these four variables (table 6). Table 7 shows generated probabalistic functions. If none of the criteria was met then the diagnosis was almost certain to be supraventricular tachycardia. If only one criterion was met it was likely to be supraventricular tachycardia. If two criteria were met the diagnosis was likely to be ventricular tachycardia. If three or four of the criteria were met the diagnosis was almost certain to be ventricular tachycardia. Figure 6 shows the logistic curve generated by this analysis. The points on the curve for none, one, or two criteria present are plotted. With no criteria met then $B X$ is -6.92 , the value of "constant", the constant term, and the

Figure 3 Predictive waveforms in lead aVF in "right bundle branch block" pattern tachycardia shown separately for ventricular and supraventricular tachycardia.
AVF 'right bundle branch block' pattern

Waveforms diagnostic of VT

9 ar 10 ORs

Waveforms diagnostic of SVT

$2 . \mathrm{Rs}$
$8 \mathrm{RR}$
$12 \mathrm{RS}$

probability of the diagnosis being ventricular tachycardia approaches zero. If the only criterion met is a myocardial infarction then $B X=-6.92+6.30=-0.62$ and so $P=$ $1 / 1+\left(\mathrm{e}^{-B X}\right)=1 / 1+\left(\mathrm{e}^{0.62}\right)=0.35$. The probability of the diagnosis being ventricular tachycardia is therefore $35 \%$ if the only criterion met is that the patient has had a past myocardial infarction. Applying these criteria back to the original data achieved a $93 \%$ predictive accuracy. This was increased to $95 \%$ by adding into the model independent $P$ waves and ventricular extrasystoles with the same QRS configuration as in tachycardia. These tests will need to be repeated prospectively.

Table 8 shows the result of multivariate analysis using the a priori electrocardiographic classification, and the result when these were combined with the significant clinical variables. Table 9 is the final analysis with just the combined significant variables. Table 10 gives the generated probabilities as seen in table 7 . When these criteria were applied back to the original data the predictive accuracy achieved was $84 \%$.

\begin{tabular}{|c|c|c|c|}
\hline \multicolumn{4}{|c|}{ AVF 'left bundle branch block' pattern } \\
\hline \multicolumn{4}{|c|}{ Waveforms diagnostic of VT } \\
\hline & ber & Waveform & Description \\
\hline 1 & $\mathbf{R}$ & & Single $R$ wave \\
\hline 5 & rSR' & & $R^{\prime}>r$ \\
\hline 6 & RSR' $^{\prime}$ & & $R^{\prime}=R$ \\
\hline 7 & QS & & as \\
\hline 8 & $q R$ & & $R>q$ \\
\hline \multicolumn{4}{|c|}{ Waveforms diagnostic of SVI } \\
\hline 2 & Rs & & $R>s$ \\
\hline 3 & rS & & $S>r$ \\
\hline
\end{tabular}

Figure 4 Predictive waveforms in lead aVF in "left bundle branch block" pattern tachycardia shown separately for ventricular and supraventricular tachycardia. 
Figure 5 Predictive waveforms in lead V1 shown separately for ventricular and supraventricular tachycardia.
V1

SWaveforms diagnostic of VT

Number Waveform Description

$1 \mathrm{R}(\mathrm{Single} \mathrm{R}$ wave

2 Rs

$4 \mathrm{RSr}^{\prime}$

$8 \quad q R$

9 Or

10 QRs

11 qRS

$124 X$

Waveforms diagnostic of SVT

3 rS

$5 \quad r S R^{\prime}$

6 RSR'

7 as

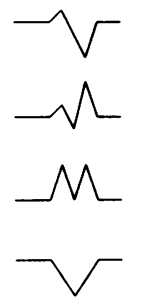

$S>r$

$R^{\prime}>r$

$R^{\prime}=R$

as

\section{Discussion}

Previous investigators have identified many clinical and electrocardiographic criteria that are useful in the differential diagnosis of broad complex tachycardia. We have shown that many of these criteria are interrelated. The use of multivariate analysis allowed identification of the independent predictors in this study group.

We studied a series of consecutive patients referred for electrophysiological evaluation. The findings may not be directly applicable to all patients with broad complex tachycardias, but referral patterns probably reflect physician preference rather than patient selection. We therefore believe that these patients are broadly representative of those presenting to accident and emergency departments. Ideally, however, the results of this study need to be confirmed in a further prospective study, in which an attempt could be made to reduce further any selection bias. This has not been done with any previous study.
Table 4 Success of assigned waveforms and a priori waveforms in the diagnosis of ventricular tachycardia (VT) or supraventricular tachycardia (SVT)

\begin{tabular}{|c|c|c|c|c|c|}
\hline \multirow{3}{*}{$\begin{array}{l}\text { Correct diagnosis } \\
\text { in leads }\end{array}$} & \multirow{2}{*}{\multicolumn{2}{|c|}{ True diagnosis }} & \multicolumn{3}{|c|}{ Predictive power for $V T$} \\
\hline & & & \multirow{2}{*}{$\begin{array}{l}\text { Sensitivity } \\
(\%)\end{array}$} & \multirow{2}{*}{$\begin{array}{l}\text { Specificity } \\
(\%)\end{array}$} & \multirow{2}{*}{$\begin{array}{l}\text { Predictive } \\
\text { Accuracy } \\
(\%)\end{array}$} \\
\hline & $V T$ & $S V T$ & & & \\
\hline \multicolumn{6}{|c|}{ Success of assigned waveforms } \\
\hline $\begin{array}{l}\text { I } \\
\text { aVF } \\
\text { V1 } \\
\text { V6 }\end{array}$ & $\begin{array}{l}39 / 69 \\
54 / 69 \\
35 / 69 \\
37 / 69\end{array}$ & $\begin{array}{l}24 / 33 \\
20 / 33 \\
28 / 33 \\
29 / 33\end{array}$ & $\begin{array}{l}57 \\
78 \\
51 \\
54\end{array}$ & $\begin{array}{l}73 \\
61 \\
85 \\
88\end{array}$ & $\begin{array}{l}61 \\
73 \\
62 \\
65\end{array}$ \\
\hline $\begin{array}{l}\text { V1 } \\
\text { V6 }\end{array}$ & $\begin{array}{l}57 / 69 \\
41 / 69\end{array}$ & $\begin{array}{c}\text { uccess of } \\
23 / 33 \\
26 / 33\end{array}$ & $\begin{array}{l}\text { ri waveforms } \\
83 \\
59\end{array}$ & $\begin{array}{l}70 \\
79\end{array}$ & $\begin{array}{l}78 \\
66\end{array}$ \\
\hline
\end{tabular}

Table 5 Multivariate analysis: constant is the constant term, $\beta$ is the coefficient entered into the logit equation, and the $p$ value is the significance of the variable

\begin{tabular}{|c|c|c|}
\hline & $\beta$ & p value \\
\hline \multicolumn{3}{|c|}{ Clinical variables alone } \\
\hline $\begin{array}{l}\text { Constant } \\
\text { Age } \\
\text { MI } \\
\text { Hypotension } \\
\text { Smoking } \\
\text { CTR > } 0.55\end{array}$ & $\begin{array}{c}-1.93 \\
0.027 \\
2.64 \\
1.10 \\
0.589 \\
2.46\end{array}$ & $\begin{array}{l}0.015 \\
0.19 \\
0.027 \\
0.13 \\
0.36 \\
0.027\end{array}$ \\
\hline \multicolumn{3}{|c|}{ Electrocardiographic criteria alone } \\
\hline $\begin{array}{l}\text { Constant } \\
\text { Tachycardia: }\end{array}$ & $-4 \cdot 65$ & $0 \cdot 185$ \\
\hline $\begin{array}{l}\text { QRS width } \\
\text { RR interval }\end{array}$ & $\begin{array}{l}-0.0089 \\
-0.0072\end{array}$ & $\begin{array}{l}0 \cdot 65 \\
0 \cdot 18\end{array}$ \\
\hline $\begin{array}{l}\text { Configuration: } \\
\text { Kindwall } \\
\text { Lead I } \\
\text { Lead aVF } \\
\text { Lead V1 } \\
\text { Lead V6 } \\
\text { Axis tachycardia } \\
\text { Axis shift }\end{array}$ & $\begin{array}{l}2 \cdot 56 \\
0 \cdot 345 \\
3 \cdot 74 \\
3 \cdot 39 \\
1 \cdot 66 \\
0.46 \\
3 \cdot 42\end{array}$ & $\begin{array}{l}0.0012 \\
0.67 \\
0.00041 \\
0.0045 \\
0.112 \\
0.59 \\
0.000698\end{array}$ \\
\hline \multicolumn{3}{|c|}{$\begin{array}{l}\text { Significant electrocardiographic and } \\
\text { clinical variables }\end{array}$} \\
\hline $\begin{array}{l}\text { Constant } \\
\text { MI } \\
\text { CTR > } 0.55 \\
\text { Kindwall } \\
\text { Lead aVF } \\
\text { Lead V1 } \\
\text { Axis shift }\end{array}$ & $\begin{array}{r}-6.97 \\
5.67 \\
2.04 \\
0.59 \\
4.32 \\
3.18 \\
2.21\end{array}$ & $\begin{array}{l}0.0002 \\
0.0034 \\
0.418 \\
0.55 \\
0.00042 \\
0.0026 \\
0.00035\end{array}$ \\
\hline
\end{tabular}

CTR, cardiothoracic ratio; $\mathrm{MI}$, myocardial infarction.

Many of the results of univariate analysis in this study are in accord with previously published data. In the paper by Baerman and colleagues in 1987, an age greater than 35 years and a history of previous myocardial infarction, angina pectoris, or congestive cardiac failure all had positive predictive values of greater than $95 \%$ for the diagnosis of ventricular tachycardia. ${ }^{3}$ In our study, smoking, haemodynamic collapse during the attack, and previous cardiac surgery were also associated with the diagnosis of ventricular tachycardia.

Many of the electrocardiographic criteria have been described before. The QRS width during tachycardia was described by Wellens and colleagues in 1978, who found that a width of greater than $140 \mathrm{~ms}$ predicted ventricular tachycardia. ${ }^{4}$ In the present series five of the 33 patients with supraventricular tachycardia had a QRS width greater than $140 \mathrm{~ms}$, either because of eccentric anterograde conduction through an accessory pathway (three patients) or an intraventricular conduction delay (two patients). Independent $P$ waves are mentioned in all reports of the diagnosis of broad complex tachycardia. If correctly identified they are almost $100 \%$ specific for ventricular tachycardia with a high sensitivity (80-90\%). Their identification on the electrocardiogram, however, is subjective and it is probably necessary to confirm the presence of independent atrial activity by some other method. Extrasystoles with the same QRS configuration as that seen during tachycardia were $100 \%$ specific for ventricular tachycardia, but only had a sensitivity of $17 \%$.

Wellens and colleagues showed that left axis deviation in the presence of "right bundle branch block" pattern was a useful sign of ventricular tachycardia. ${ }^{4}$ Dancy and Ward stated that left axis deviation during any broad 
Table 6 Combined significant variables

\begin{tabular}{lrl}
\hline & $\beta$ & $p$ value \\
\hline Constant & -6.92 & 0.0003 \\
MI & 6.30 & 0.0009 \\
Axis shift & 4.45 & 0.00009 \\
Lead aVF & 4.53 & 0.00001 \\
Lead V1 & 3.44 & 0.0009 \\
\hline MI myocardial infarction &
\end{tabular}

complex tachycardia is indicative of ventricular tachycardia. ${ }^{5}$ The present paper confirms both these observations, but also suggests that right axis deviation is an equally useful sign, especially in the presence of "left bundle branch block" pattern tachycardia. However, a change in axis between sinus rhythm and tachycardia of more than $40^{\circ}$, either to the right or to the left, was a more powerful predictor of ventricular tachycardia.

The paper by Dongas and colleagues suggested that an identical bundle block pattern in sinus rhythm and in tachycardia is diagnostic of supraventricular tachycardia. ${ }^{6}$ However, only one patient with supraventricular tachycardia with bundle branch block both in sinus rhythm and in tachycardia was seen in this study. There were, however, two patients who had very similar "right bundle branch block" patterns in sinus rhythm and in ventricular tachycardia.

Previous papers have examined the configuration of the chest leads. ${ }^{47}$ This study confirms that various waveforms in leads V1 and V6 in "right bundle branch block" pattern tachycardia are diagnostic. A single $R$ wave or biphasic waveform in lead V1 was highly suggestive of ventricular tachycardia, while an RSR' pattern was suggestive of supraventricular tachycardia unless the amplitude of the $R$ wave was greater than that of the $R^{\prime}$ wave. In lead V6 an R or RS pattern, where the $R$ wave was greater in amplitude than the $S$ wave, was suggestive of supraventricular tachycardia, while a $Q$ wave or an RS pattern with a dominant $S$ wave was suggestive of ventricular tachycardia. In this study lead I was not helpful in most patients, though in "left bundle branch block" pattern tachycardia a QS or qR was suggestive of ventricular tachycardia. Lead aVF was the most useful of the four leads, with a $72 \%$ predictive accuracy for ventricular tachycardia. In this lead a QS pattern was seen in $31 / 69(45 \%)$ patients with ventricular tachycardia and only 5/33 (15\%) patients with supraventricular tachycardia. The criteria for the analysis of "left bundle branch block"

Table 7 Probabilities (\%) that a broad complex tachycardia is ventricular in origin tested by the logistic regression equation if one or two of the four criteria are present

\begin{tabular}{llllll}
\hline & Alone & $+M I$ & + Shift & $+a V F$ & V1 \\
\hline MI & 35 & & 98 & 98 & 95 \\
Shift & 8 & 98 & & 88 & 72 \\
aVF & 8 & 98 & 88 & 74 & 74 \\
V1 & 3 & 95 & 72 & 74 &
\end{tabular}

If no criteria are met the probability that the diagnosis is ventricular tachycardia is less than $1 \%$. If three or four criteria are met the probability that the diagnosis is ventricular tachycardia is greater than $99 \%$.

MI, myocardial infarction.

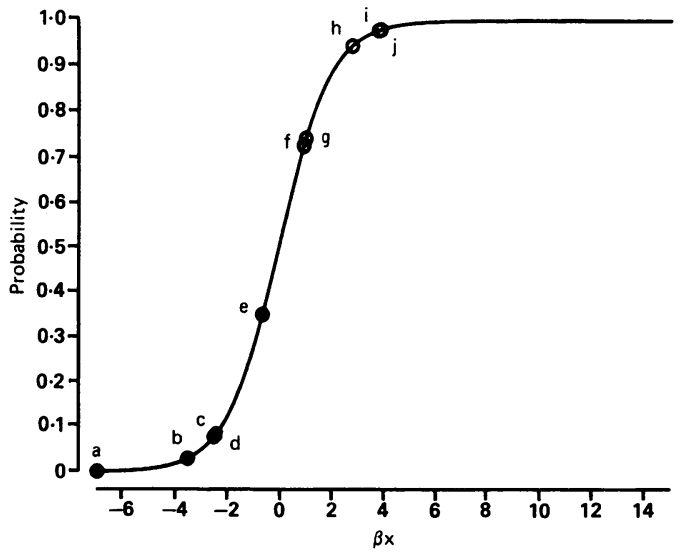

Figure 6 Logistic curve of $B X$ (the sum of the equation) versus probability (the probability of the diagnosis being ventricular tachycardia) produced by the analysis with the points produced by the various combinations of the criteria met. The closed circles represent none or only one criterion present when the probability of the diagnosis of ventricular tachycardia is less than $50 \%$. The open circles represent two criteria being present, and the probability of the diagnosis being ventricular tachycardia is greater than $50 \%$. Three or four criteria make the probability of the diagnosis being ventricular tachycardia approach $100 \%$. $a=$ no criterion; $b=V 1 ; c=$ axis shift $; d=a V F ; e=M I ; f=V 1+$ axis shift $; g=V 1$ $+a V F ; h=M I+V 1 ; i=M I+$ axis shift $; j=M I$ $+a V F$.

pattern tachycardia put forward by Wellens and colleagues and tested by Kindwall et al were also included in the multivariate analysis. ${ }^{12}$

When we tried to enter this data into multivariate analysis we encountered various problems. The main one was how to enter the different waveforms. The solution we used was to dichotomise them on the basis of the univariate analysis, so that waveforms seen more often with ventricular tachycardia or with supraventricular tachycardia were designated as being in favour of ventricular tachycardia or supraventricular tachycardia respectively. This method is not perfect, but alternative solutions such as converting each waveform, in each lead, to a risk ratio based on the proportion of VT/SVT has greater theoretical problems. It would convert non-continuous data to con-

Table 8 Multivariate analysis with a priori criteria

\begin{tabular}{lcl}
\hline & $\beta$ & $p$ value \\
\hline \multicolumn{2}{c}{ A priori electrocardiographic criteria alone } \\
Constant & -3.52 & 0.064 \\
Tachycardia: & 0.016 & \\
QRS width & -0.0036 & 0.15 \\
RR interval & & 0.41 \\
Configuration: & 2.4 & \\
Lead V1 & 0.55 & 0.001 \\
Lead V6 & 0.61 & 0.41 \\
Axis tachycardia & 2.05 & 0.33 \\
Axis shift & & 0.0013 \\
\multicolumn{1}{c}{ Significant a priori electrocardiographic } \\
and clinical variables & \\
Constant & -2.81 & 0.0024 \\
MI & 3.68 & 0.0028 \\
CTR > 0.55 & 2.01 & 0.080 \\
Lead V1 & 1.78 & 0.0087 \\
Axis shift & 2.34 & 0.0018 \\
\hline
\end{tabular}

CTR, cardiothoracic ratio; MI, myocardial infarction. 
Table 9 Combined significant variables

\begin{tabular}{lrl}
\hline & $\beta$ & $p$ value \\
\hline Constant & -2.73 & 0.0002 \\
MI & 3.86 & 0.001 \\
Axis shift & 2.55 & 0.00043 \\
Lead V1 & 1.87 & 0.0049 \\
\hline
\end{tabular}

MI, myocardial infarction.

tinuous data and would make the clinical use of the criteria even more difficult. The waveform criteria in leads V1 and V6 which were used for the diagnosis of "right bundle branch block" pattern tachycardias as described by Wellens and colleagues ${ }^{4}$ are essentially the same as those generated by this study but they cannot be used alone because they do not include all possible waveforms. Because of the theoretical problems of deriving the electrocardiographic criteria from the data we also tested an a priori classification of leads V1 and V6. This showed that lead V1, but not lead V6, was an important independent predictor of the origin of a broad complex tachycardia, with similar waveform criteria as the derived classification. Concordance, either negative or positive, across the chest leads was not analysed separately from waveforms in leads V1 or V6 because it would be a derivative variable. Axis and axis change were dichotomised because the circular nature of the axis does not allow their use as continuous variables.

The second problem was that of variables that were obviously dependent on each other. The multivariate model we used was based on the premise that the variables show some independence. This means that the very dependent variables must be eliminated. Because all patients with angina, coronary artery surgery, or congestive heart failure had had either a myocardial infarction or an abnormal cardiothoracic ratio or both we did not enter these variables into the multivariate analysis. Independent $P$ waves and identical ventricular extrasystoles posed a different problem. Both these variables in this data set were $100 \%$ specific. In iterations the model found that these variables were always associated with ventricular tachycardia but with a low sensitivity and so they had no effect on the predictive power of the other variables. These two variables, therefore, produced a very high coefficient $(\beta)$ and a $\mathbf{P}$ value approaching unity. When they were added to the final analysis these two variables increased the diagnostic accuracy of the model from $93 \%$ to $95 \%$.

In the present study the analysis of the

Table 10 Probabilities (\%) that a broad complex tachycardia is ventricular in origin tested by the logistic regression equation if one or two of the four criteria are present

\begin{tabular}{lllll}
\hline & Alone & $+M I$ & + Shift & V1 \\
\hline MI & 75 & & 97 & 95 \\
Shift & 45 & 97 & 85 & 85 \\
V1 & 29 & 95 & & \\
\hline
\end{tabular}

If no criteria are met the probability that the diagnosis is ventricular tachycardia is less than $1 \%$.

If three or four criteria are met the probability that the diagnosis is ventricular tachycardia is greater than $99 \%$. MI, myocardial infarction. electrocardiograms was not performed blindly. The validity of the relatively soft sign of independent $P$ waves was not adequately tested and would therefore benefit from further research. As with previous studies, ${ }^{157}$ blinding the observer to the other electrocardiographic signs was not thought necessary because these criteria were all objective measurements.

Our multivariate analysis showed the interdependence of many of the clinical and electrocardiographic features. A history of myocardial infarction and an abnormal cardiothoracic ratio were two independent clinical predictors of ventricular tachycardia. The QRS patterns in leads $\mathrm{VVF}, \mathrm{V1}$, and $\mathrm{V6}$, as well as the criteria of Kindwall and colleagues and the change in QRS axis were all independent electrocardiographic predictors of ventricular tachycardia. When the electrocardiogram and clinical data were added together the independent predictors were a history of myocardial infarction, the QRS complex configurations in leads $\mathrm{aVF}$ and $\mathrm{V} 1$, and change in QRS axis. Thus the criteria of Kindwall and colleagues did not seem to be independent of a history of myocardial infarction. ${ }^{2}$ QRS complex configuration in lead V6 was not an independent predictor of ventricular tachycardia, though it is widely used. ${ }^{4}$ The QRS configuration in lead aVF was an important independent preditor of the origin of the tachycardia. Lead aVF has not been previously analysed in this context and these findings need confirmation.

The four independent variables when applied back to the data achieved a $93 \%$ predictive accuracy (dropping to $84 \%$ if only an a priori electrocardiographic classification is used). The addition of the two very specific variables, ventricular extrasystoles of the same configuration and independent $\mathbf{P}$ waves, increases the diagnostic accuracy of the model by only $2 \%$. The fact that the predictive accuracy did not approach $100 \%$ supports the use of other methods as adjuncts to the diagnosis. Attempted termination by adenosine and Doppler analysis of the atrioventricular relation may allow more accurate analysis. ${ }^{12}{ }^{13}$ The use of adjunctive diagnostic methods is particularly important if only one or two major diagnostic criteria are met because the diagnosis is then still in doubt (with probabilities of $3-35 \%$ or $72-98 \%$ respectively for the diagnosis of ventricular tachycardia). The diagnosis is virtually certain if either none (supraventricular tachycardia) or three or four criteria are met (ventricular tachycardia). A computer based expert system using these four criteria would be extremely useful in clinical practice. Alternatively, these criteria could form the basis of a simple clinical algorithm, which could be made available in accident and emergency departments.

The analysis using the a priori criteria confirms that lead V1, axis shift, and a history of a myocardial infarction are the three independent predictive variables. Their combined predictive accuracy of $84 \%$ is lower than that seen with the derived electrocardiographic criteria, probably because of the exclusion of lead aVF. 
We found that a history of myocardial infarction, axis shift during tachycardia, and the QRS configuration in lead V1 were the independent predictors of the origin of a broad complex tachycardia. The QRS configuration in lead aVF also seems to be both an important univariate and independent multivariate predictor of the origin of a broad complex tachycardia, but this needs prospective confirmation.

The statistics in this study were performed in conjunction with John Micklewright, $\mathrm{PhD}$, lecturer in microeconometrics at Queen Mary's College and Associate Professor, University of Florence. His specialty is the application of statistics to small population groups.

1 Wellens $\mathrm{HJJ}$, Brugada P. Diagnosis of ventricular tachycardia from the twelve lead electrocardiogram. Cardiol Clin 1987;5:511-26.

2 Kindwall EK, Brown J, Josephson ME. Electrocardiographic criteria for ventricular tachycardia in wide complex left bundle branch block morphology tachycardia. plex left bundle branch block

3 Baerman JF, Morady F, DiCarlo LA, de Buitler M. Differentiation of ventricular from supraventricular tachycardia with aberration: value of the clinical history. Ann Emerg Med 1987;16:40-3.

4 Wellens HJJ, Bar FWHM, Lie KI. The value of the electrocardiogram in the differential diagnosis of a tachycardia with a widened QRS complex. Am J Med 1978;64:27-33.

5 Dancy $M$, Ward DE. Clinical algorithm for the diagnosis of ventricular tachycardia. $B M J 1985 ; 291: 1036-9$.

6 Dongas J, Lehmann MH, Mahmud R, Denker S, Soni J, Akhtar M. The value of pre-existing bundle branch block in the electrocardiographic differentiation of supraventricular from ventricular origin of wide complex ventricular from . Cardiol 1985;55:717-21.

7 Marriott HJL, Sandler IA. Criteria, old and new, for Marriott HJL, Sandler IA. Criteria, old and new, for aberrant ventricular conduction in the presence of atrial aberrant ventricular conduction in the presen
fibrillation. Prog Cardiovasc Dis 1966;9:18-28.

8 Tchou P, Young P, Mahmud R, Denker S, Jazayeri M, chou P, Young P, Mahmud R, Denker S, Jazayeri M,
Akhtar M. Useful clinical criteria for the diagnosis of Akhtar M. Useful clinical criteria for the diag
ventricular tachycardia. Am J Med 1988;84:53-6.

9 Melfi CA. Limdep: a review. Journal of Applied Econometrics 1987;2:251-5.

10 Diamond GA, Pollock BH, Work JW. Clinical decisions and computers. J Am Coll Cardiol 1987;9:1385-96.

11 Willems JL, Lesaffre E. Comparison of multigroup logistic and linear discriminant ECG and VCG classification. Electrocardiol 1987;20:83-92.

12 Griffith MJ, Linker NJ, Ward DE, Camm AJ. Adenosine in the diagnosis of broad complex tachycardias. Lancet 1988;i:672-5.

13 Griffith MJ, Mehta D, Ward DE, Camm AJ. Doppler diagnosis of broad complex tachycardias. Am Heart $J$ 1988;116:555-7.

\section{NOTICES}

1991

The Fourth Annual International Symposium on New Technologies in Cardiovascular Ultrasound will be held at the Mayo Clinic, Rochester, Minnesota, USA, on 15 to 18 September (Satellite Teleconference: Mayo Jacksonville, Mayo Scottsdale, Sao Paulo, Brazil, and Buenos Aires, Argentina): Fax 5072840532 ; Tel 5072842509 or 1800 3232688 .

The. Fifth International Workshop on Future Directions in Interventional Cardiology will be held in Santa Barbara, California, on 20 to 22 September: The American College of Cardiology, 9111 Old Georgetown Road, Bethesda, MD 20814, USA (Fax: 301 897 9745; Tel: 301897 2695).

The Third International Workshop on Magnetic Resonance Angiography will be held in L'Aquila on 13 October: Scientific Secretariat, Dr Paolo Pavone, Department of Radiology, University of L'Aquila, Ospedale Collemaggio, 67100 L'Aquila, Italy (Fax: 39 862 410997; Tel: 39862 26164).
The First Symposium on Magnetic Resonance Imaging of the Cardiovascular System will be held in Rome on 14 to 16 October: Scientific Secretariat, Dr Paolo Pavone, Department of Radiology, University of L'Aquila, Ospedale Collemaggio, 67100 L'Aquila, Italy (Fax: 39862 410997; Tel: 39 862 26164).

An International Symposium and Workshop on Transoesophageal Echocardiography in Congenital Heart Disease will be held in Edinburgh on 23 and 24 November: The Secretary, Symposium "TEE in Congenital Heart Disease", Department of Paediatric Cardiology, Royal Hospital for Sick Children, Sciennes Road, Edinburgh EH9 1LF.

1992

The Annual Meeting of the British Cardiac Society will take place at the Harrogate International Centre on 26 to 29 May.

The Ninth International Congress of Histochemistry and Cytochemistry will be held in Maastricht on 30 August to 5 September: Organising Secretariat, Professor F C S Ramaekers, Department of Molecular Cell Biology, University of Limburg, PO Box 616, $6200 \mathrm{MD}$ Maastricht, The Netherlands (Fax: 3143 437640; Tel: 3143 888642). 